\title{
Resenha
}

\section{Indicadores de sustentabilidade: uma análise comparativa.}

\author{
José Antonio Puppim de Oliveira*
}

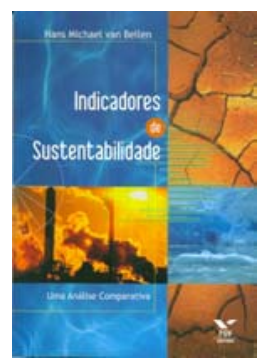

VAN BELLEN, Hans Michel. Indicadores de sustentabilidade: uma análise

comparativa. Rio de Janeiro: Editora FGV, 2005. 253 p.

O desenvolvimento sustentável é hoje um dos temas de maior relevância nos debates travados na área de administração e das outras ciências sociais aplicadas. Verificar se estamos no caminho da sustentabilidade é uma das principais questões levantadas nessa discussão, ou seja, saber que indicadores podem ser estabelecidos para saber se de fato estamos na direção do desenvolvimento sustentável. Trata-se, portanto, de questionarmos o quão sustentável é o nosso dia-a-dia, o das organizações, das cidades, dos países e, mesmo, de um ponto de vista global.

Indicadores de sustentabilidade: uma análise comparativa é resultado de uma pesquisa para a tese de doutorado de seu autor, apresentada na Universidade Federal de Santa Catarina (UFSC) e na Universidade de Dortmund (Alemanha), e nos ajuda muito a pensar nas alternativas existentes, pois analisa todos os aspectos que envolvem o problema.

Inicialmente, Van Bellen situa o leitor historica e conceitualmente nos debates sobre desenvolvimento sustentável e indicadores de sustentabilidade. Contudo, vai além da demonstração de embasamento teórico e da pura descrição das diferentes metodologias existentes para avaliação de sustentabilidade. $\mathrm{O}$ autor busca a opinião de alguns dos maiores especialistas do mundo e, depois, faz uma análise comparativa dos três principais sistemas internacionais de indicadores de sustentabilidade apontados por esses especialistas: Ecological footprint method, Dashboard of sustainability e Barometer of sustainability. Ele compara esses três sistemas em diferentes categorias como escopo (ecológico, social, econômico e institucional), esfera (global, nacional, regional, organizacional e individual), dados utilizados na elaboração dos indicadores, participação dos stakeholders na elaboração e definição dos indicadores, e a interface, ou seja, a capacidade dos vários tipos de usuários interpretarem os indicadores para avaliar a sustentabilidade.

A obra de Van Bellen compatibiliza o rigor acadêmico esperado de uma tese de doutorado com o caráter acessível de um texto voltado para leigos que querem aprender a construir indicadores de sustentabilidade. É uma leitura para acadêmicos, estudantes ou profissionais da área de desenvolvimento sustentável, e mesmo de outras áreas, que queiram saber mais e levar a discussão sobre essa questão fundamental para seus respectivos campos de atuação. Espero que Indicadores de sustentabilidade: uma análise comparativa contribua para a elaboração de sistemas de indicadores de desenvolvimento sustentável no Brasil, ainda bastante limitados por aqui. Mais do que isso, a expectativa é a de que a obra de Van Bellen sensibilize acadêmicos e aqueles que tem poder de decisão, não apenas para a questão do desenvolvimento sustentável, mas também sobre a importância de avaliar se estamos indo ao não nessa direção.

* Professor da EBAPE/FGV. Ph.D. em Planejamento pelo Massachusetts Institute of Technology - MIT, EUA. E-mail: puppim@fgv.br. Endereço: Praia de Botafogo, 190 sala 507. CEP: 22253-900 - Rio de Janeiro - RJ. 